\title{
Pre-aspiration and the problem of zeroes: Phonological rules can be variable ${ }^{1}$
}

\author{
Míša Hejná \\ Aarhus University
}

\begin{abstract}
Pre-aspiration can be defined as a period of glottal friction, [h], which is found in the sequences of sonorants and phonetically voiceless obstruents, as in map $\left[\mathrm{ma}^{\mathrm{h}} \mathrm{p}^{\mathrm{h}}\right]$ (e.g. in Welsh English, Hejná 2015). This chapter problematises the default approach to pre-aspiration shown in a number of studies, which assume that unless pre-aspiration applies obligatorily it is subject only to phonetic constraints rather than, at least potentially, both phonetic and phonological constraints. As a result, instances where pre-aspiration reaches the duration of $0 \mathrm{~ms}$, i.e. where it does not apply $\left(\mathrm{mat}\left[\mathrm{mat}^{\mathrm{s}}\right]\right)$, are typically included in the analyses of its phonetic conditioning. This can be problematic in cases where zero values reflect a variable phonological rule rather than the output of solely phonetic constraints as such an approach may obscure our understanding of the constraints on pre-aspiration.
\end{abstract}

[I] t may be time to consider the zero.

(Tanning 2011)

\section{Introduction}

This chapter problematises the default approach to a phenomenon known as pre-aspiration (defined in Section 2 below). As Sections 3-4 discuss, pre-aspiration studies frequently assume that, unless pre-aspiration applies

1 I am grateful to Anna Jespersen for comments on an earlier version of this chapter. As always, I am also grateful to Yuni Kim, who introduced me to the world of phonological theory and the phonetics-phonology interface through frequent conversations in 20122015. I would also like to thank the reviewer.

Ken Ramshøj Christensen, Henrik Jørgensen \& Johanna L. Wood (eds.). 2019.

The Sign of the V-Papers in Honour of Sten Vikner.

Dept. of English, School of Communication \& Culture, Aarhus University, pp. 227-242, doi:10.7146/aul.348.97. (C) The author(s) 
obligatorily (in $100 \%$ of the appropriate contexts), it is subject to phonetic constraints rather than, at least potentially, phonetic and/or phonological constraints. ${ }^{2}$ Where pre-aspiration does not apply, its duration is then considered to be that of $0 \mathrm{~ms}$. In other words, instances where there is no pre-aspiration ( $m a t\left[\mathrm{mat}^{\mathrm{s}}\right]$ ) are typically included in the analyses of the phonetic conditioning of pre-aspiration, such as the effects of the place of articulation (/p/ vs / $/ \mathrm{vs} / \mathrm{k} /$ ) or vowel height (high vowels vs low vowels) on its duration. I argue that this can be problematic in cases where zero values do reflect a variable phonological rule rather than the output of solely phonetic constraints. I call this issue the problem of zeroes.

\section{Defining pre-aspiration}

Pre-aspiration can be defined as a period of (primarily) glottal friction found in the sequences of sonorants and phonetically voiceless obstruents. Instances of pre-aspirated obstruents in English could be transcribed as map $\left[\mathrm{ma}^{\mathrm{h}} \mathrm{p}^{\mathrm{h}}\right]$, mat $\left[\mathrm{ma}^{\mathrm{h}} \mathrm{t}^{\mathrm{s}}\right]$, and $m a c$ [ma $\left.\mathrm{k}^{\mathrm{h}}\right]$ (e.g. in Welsh English, Hejná 2015). From an articulatory point of view, the phenomenon includes a spread state of the glottis, associated with more lax phonatory settings, in which the intrinsic laryngeal muscles are more relaxed. Some languages can develop a fricative component produced in the oral cavity as well (e.g. Scottish Gaelic - e.g. Bosh 2006/2007). Regarding the voicing aspects of pre-aspiration, we find two different approaches to the phenomenon. Preaspiration defined broadly can include two phases: a voiced component and a voiceless component. The voiced component, which can be labelled local breathiness, involves the vibration of the vocal folds associated with an increased amount of airflow coming through the glottis as compared to the usual phonatory settings of the relevant pre-aspirating speaker. This results in a laxer phonatory setting, and that in turn results in a breathier phonation. The voiceless component can be labelled pre-aspiration in its narrower sense, and involves voiceless friction. In voiceless pre-aspiration, the vocal folds do not vibrate, but they are close enough to generate glottal friction. Acoustically, the voiceless component lacks periodicity in the acoustic signal in contrast to the voiced component. The voiced component differs from modal phonation acoustically in that it is associated with a more quasi-sinusoidal waveform and friction above the second formant frequencies, and general dampening of the formant structure. The two

$\overline{2}$ A combination of phonetic and phonological constraints, as well as that of different phonological constraints, is common. See Iosad (2016) for a discussion of rule scattering and further relevant references. 
phases, local breathiness and voiceless pre-aspiration, are shown in a spectrogram and a waveform in Figure 1, which displays the acoustic information of the English word backer as uttered by a speaker from Aberystwyth, mid Wales.

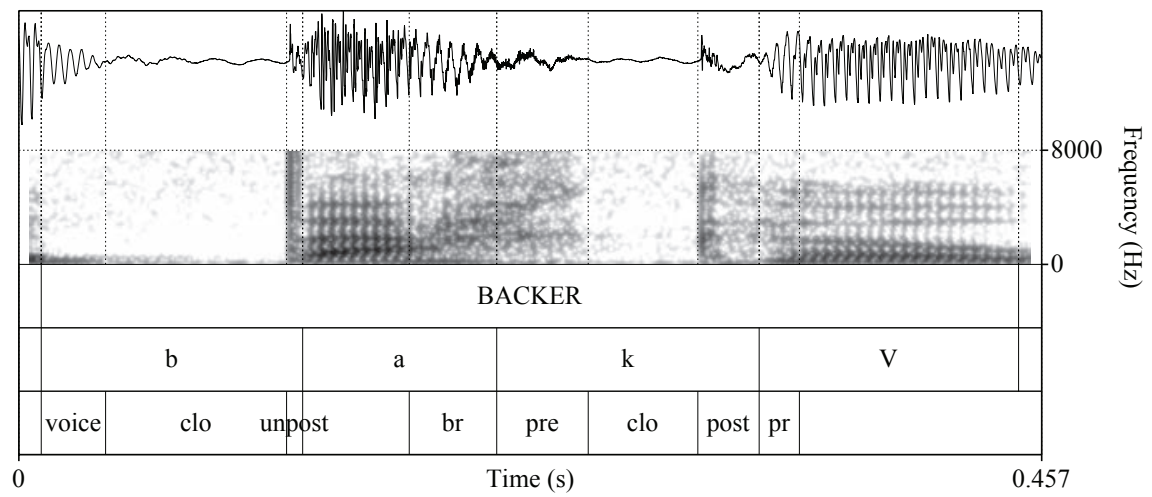

Figure 1. Identification and segmentation of pre-aspiration and local breathiness. 'clo' $=$ closure, 'unpost' $=$ unaspirated release, 'br' = pre-aspiration induced local breathiness, 'pre' $=$ voiceless pre-aspiration, 'post' $=$ post-aspirated release, ' $p r$ ' $=$ vowel-initial breathiness, ' $\mathrm{V}$ ' = unstressed vowel.

Whether both the voiced and the voiceless pre-aspiration phases are indeed treated as two phases of a single phenomenon depends on the individual study of pre-aspiration. Some researchers define pre-aspiration broadly and do not distinguish the voiced and the voiceless components in their analyses (van Dommelen 1999, 2000; van Dommelen \& Helgason 2003; Helgason \& Ringen 2008; Svantesson et al. 2005; Svantesson \& Karlsson 2012; Morris 2010; Ringen \& van Dommelen 2013; Stevens 2010, 2011; Stevens \& Hajek 2004a, 2004b). ${ }^{3}$ Others only target the voiceless component (Hejná \& Jespersen 2019; Hejná \& Kimper 2019). Some studies do not provide sufficient information for the reader to know if preaspiration involves only voiceless or also voiced glottal friction (Helgason 1998; McRobbie-Utasi 2003; Tronnier 2002). Yet we also find studies which focus on both components and distinguish these two components in the analyses (Hejná 2015; Kingston 1990; Morris \& Hejná 2019; Nance \& Stuart-Smith 2013; Ní Chasaide 1985). The last type of pre-aspiration

3 Although these authors may distinguish the two in their annotation at some point, they do not report the results separately for the two, nor is it discussed whether these pattern in the same way. 
studies typically show that the voiced and the voiceless components can display different patterns regarding their intra- and extra-linguistic conditioning (Hejná 2015; Kingston 1990; Morris \& Hejná 2019; Nance \& Stuart-Smith 2013; Ní Chasaide 1985).

Pre-aspiration is most frequently analysed in terms of its frequency of occurrence, or the rate of application: How frequently do we find pre-aspiration in the sequences of sonorants and phonetically voiceless obstruents in variety $\mathrm{X}$ ? The other frequently studied aspect of preaspiration is its duration: how long is pre-aspiration? Finally, a limited number of studies also focus on the noisiness of pre-aspiration (Gordeeva \& Scobbie 2010; Gordeeva \& Scobbie 2013; Morris \& Hejná 2019; Nance \& Stuart-Smith 2013).

\section{Pre-aspiration as a (phonologically) rare phenomenon}

It has generally been accepted that pre-aspiration is a (very) rare linguistic phenomenon (see Hejná 2015: 29-31 for an overview). The reported rarity of the phenomenon increases even further if it is phonological pre-aspiration which is considered (Clayton 2010: iii). This is because pre-aspiration has been claimed to only be of interest to phonology if it applies in $100 \%$ of the cases in which it could possibly apply and if it cues a phonological contrast. ${ }^{4}$ These assumptions are problematic not only because of the growing body of evidence showing that there are more pre-aspirating languages than previously thought, but also because the claims related to the rarity of pre-aspiration have sometimes been based on counting only those languages in which pre-aspiration is seen as phonologically relevant. However, establishing phonological relevance is not a straightforward task.

Thus, Ladefoged \& Maddieson (1996: 73) state that pre-aspiration is not "a feature [necessarily] required for distinguishing underlying forms". Contrast is undoubtedly at the centre of phonological theory, but how is contrastiveness established exactly? Hejná (2015: chapter 6) engages with this question: Phonological contrasts are well-known to be implemented

\footnotetext{
4 Much of the pre-aspiration literature (e.g. Morris 2010; Wretling, Strangert \& Shaeffler 2002) adopts the dichotomy of normative and non-normative pre-aspiration introduced by Helgason $(1999$ b , 2002). It is somewhat unfortunate that Helgason presents us with two rather different definitions of normative and non-normative pre-aspiration. According to the first definition, pre-aspiration is normative if it is phonologically relevant (Helgason 1999a) and obligatory (Helgason 1999b: 1854; 2002: 8). According to the other definition, pre-aspiration is normative if it is used by all of the speakers in a community in the same way (Helgason 2002: 21). The first definition is the one adopted also by Morris (2010) and Wretling, Strangert \& Shaeffler (2002).
} 
by a wide range of correlates and cued via a number of cues; as long as pre-aspiration contributes to the implementation of a contrast in some way, we cannot but consider it contrastive. However, pre-aspiration has been traditionally described as contrastive only in Icelandic, Faroese, Scottish Gaelic, and Lule Sami (Ladefoged \& Maddieson 1996: 70). Silverman (2003) adds three more languages in which pre-aspiration is contrastive, including Chamicuro, Oraibi Hopi, and Tarascan. In addition to the contrastively pre-aspirating languages mentioned in Ladefoged \& Maddieson (1996) and Silverman (2003), pre-aspiration has more recently been found to correlate with fortis as opposed to lenis plosives ${ }^{5}$ in Aberystwyth English (Hejná 2016), Manchester English (Hejná \& Kimper 2019), Scottish English (Gordeeva \& Scobbie 2010, 2013), in the speech of 5 speakers representing Canadian English, Irish English, Welsh English, and SSBE (Hejná \& Jespersen 2019), various dialects of Norwegian (van Dommelen 1999, Ringer \& van Dommelen 2013), San Martín Itunyoso Trique (DiCanio 2012: 252-254), Central Standard Swedish (Helgason \& Ringen 2008), and Bethesda Welsh (Morris \& Hejná 2019). Pre-aspiration has been investigated as a potential cue of the fortis-lenis contrast for Norwegian (van Dommelen 1998) and Northern England English (Hejná \& Kimper 2019) and has indeed been found to function as a cue to the contrast in these two languages. Stevens \& Hajek (2004a) also present evidence of pre-aspiration occurring in fortis geminate plosives but not the lenis ones in Italian.

Contrastiveness is nevertheless not the only gate to the realm of phonology. It has been established that variable outputs can be due to variable phonological rules (e.g. Antilla 2006; Coetzee \& Pater 2011; Guy 19991; Sebregts 2014: chapter 6, and the references therein). This means that even if a phenomenon applies in fewer than $100 \%$ of the cases, it can still be subject to phonological constraints. For instance, Coetzee \& Pater (2011) mention $\mathrm{t} / \mathrm{d}$-deletion, as in west being pronounced as [wes] rather than [west], a variable which is sensitive to phonological and morphological characteristics of the words affected (Guy 1994). This being the case, we simply cannot assume that non-obligatory application of pre-aspiration on its own justifies our choice to include zero values in our analyses of the

5 Although using the terms fortis and lenis may be controversial to some (see for instance the overview on the different uses of the terms in Ladefoged \& Maddieson 1996: 95), the two terms are adopted here as convenient labels to distinguish the two phonological series of $/ \mathrm{p}, \mathrm{t}, \mathrm{k} /$ and $/ \mathrm{b}, \mathrm{d}, \mathrm{g} /$ in order "to avoid potentially confusing situation where one speaks of voiceless voiced stops, i.e. phonologically voiced stops with no phonetic voicing" (Ní Chasaide 1985: 105). 
phonetic constraints on the phenomenon.

When the relevant literature on pre-aspiration is inspected in detail, we find that often enough pre-aspiration has not been approached from a phonological point of view, but typically from a phonetic or a predominantly sociophonetic point of view (e.g. Foulkes et al. 1999; Helgason et al 2003; Jones \& Llamas 2003; Morris 2010; Roos 1998; $\mathrm{Su}$ 2007). There is a good reason for this. Since pre-aspiration has been considered so rare, the main goal of a number of pre-aspiration studies is to acknowledge that the phenomenon occurs in a language/variety in the first place. Furthermore, sociophonetic analyses often concentrate on issues other than contrastiveness. Future studies therefore remain to show whether pre-aspiration is contrastive and/or otherwise phonologically conditioned in the relevant languages/varieties. The next section focuses on the problem of zeroes, and the problem of potentially conflating phonetic and phonological outputs in general.

\section{The problem of zeroes}

Before the problem of zeroes is discussed here in detail, it is important to outline some of the assumptions made in this chapter. Firstly, as perhaps obvious by this point, phonetics and phonology are seen as distinct, i.e. there is a difference between phonetics and phonology. Secondly, diagnosing whether a phenomenon is subject to phonetic as opposed to phonological phenomena can be determined by a careful inspection of the acoustic or articulatory evidence available. If variation in a certain sound can be explained via physiological, aerodynamic, or acoustic accounts, then this variation is considered a phonetic type of variation. Thus, for instance, if there is a positive correlation between the duration of aspiration and the posteriority of the articulation, across and within different places of articulation (e.g. $/ \mathrm{p} /, / \mathrm{t} /, / \mathrm{k} /$ ), it is a phonetic type of conditioning we are dealing with. On the other hand, if there is no such correlation within the category of $/ \mathrm{p} /$, the variation found cannot be accounted for by phonetic explanations (alone). These two assumptions are in line with other studies focusing on the phonetics-phonology interface (e.g. Cohn 1998, 2006; Keating 1990, 1996; Strycharczuk 2012; Turton 2014, 2015, 2017; contra to Ohala 1990, depending on the exact definition of the term). As shown by the studies referenced here, phonetically conditioned variation displays gradient effects, whereas phonologically conditioned variation displays phonetically abrupt effects in the temporal-spacial domain of the 
specific acoustic and/or articulatory properties that are being quantified (e.g. aspiration duration, formant value associated with a certain phoneme, tongue root retraction, glottal open/contact quotient, etc.).

Let us return to the problem of zeroes in the context of pre-aspiration studies. Frequency of occurrence, at least at first, seems a relatively simple way of quantifying pre-aspiration. If pre-aspiration reaches the duration of $0 \mathrm{~ms}$, it is absent from the signal, and should be counted as a negative instance of the phenomenon - its absence. Any other values should then be considered positive cases of pre-aspiration. Although this is the mainstream approach to quantifying the frequency of application of preaspiration, there are nevertheless researchers who have set a point higher than $0 \mathrm{~ms}$ to distinguish pre-aspiration as "present" and "absent". Thus, Helgason (2002: 152) counts pre-aspiration as present only if it reaches 15 ms and higher. Similarly, when quantifying the frequency of occurrence of pre-aspiration in their Scottish English data, Gordeeva \& Scobbie (2010: 13) set the threshold for annotating pre-aspiration as present only if it reaches $30 \mathrm{~ms}$, which is motivated by perceptual evidence related to preaspiration in Norwegian (van Dommelen 1998): If the listeners can register pre-aspiration only if it has at least $30 \mathrm{~ms}$, we should only count instances of $30 \mathrm{~ms}$ and higher as positive instances of pre-aspiration. Nonetheless, this approach is problematic. Firstly, we do not in fact have the perceptual evidence relevant for most pre-aspirating languages. Gordeeva \& Scobbie (2010) use perceptual evidence available for Norwegian for analyses of English pre-aspiration. We can expect perceptual thresholds to vary from language to language (and from accent to accent). Indeed, if we inspect the perceptual literature available, this concern proves to be substantiated (van Dommelen 1998; Hejná \& Kimper 2019; Pind 1996a, 1996b, 1998). In addition, however, and perhaps more importantly, we may be interested in factors such as biomechanical constraints on pre-aspiration, in which case all the values measured above $0 \mathrm{~ms}$ are surely of interest to our understanding of why the phenomenon patterns the way it does, irrespective of the perceptual properties of the phenomenon.

There is nevertheless a more serious problem related to the importance of zero values. This problem is linked with the second aspect of preaspiration which is usually quantified in pre-aspiration studies: preaspiration duration. As shown in Figure 2, when we inspect the duration of (voiceless) pre-aspiration in 12 speakers of English spoken in Aberystwyth, mid Wales (see Hejná 2015 for more details on these speakers), we find that all of the twelve individuals show that zero values pattern rather differently 
from the non-zero values.
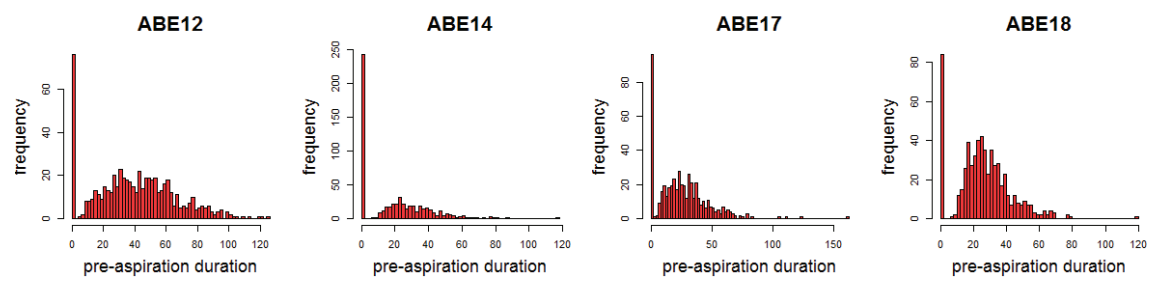

ABE24

ABE31

ABE33
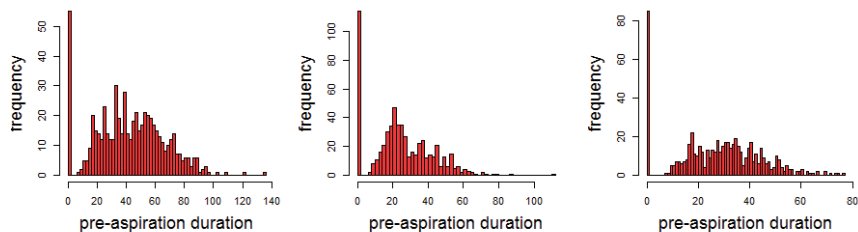

ABE37

ABE45

ABE46

ABE50
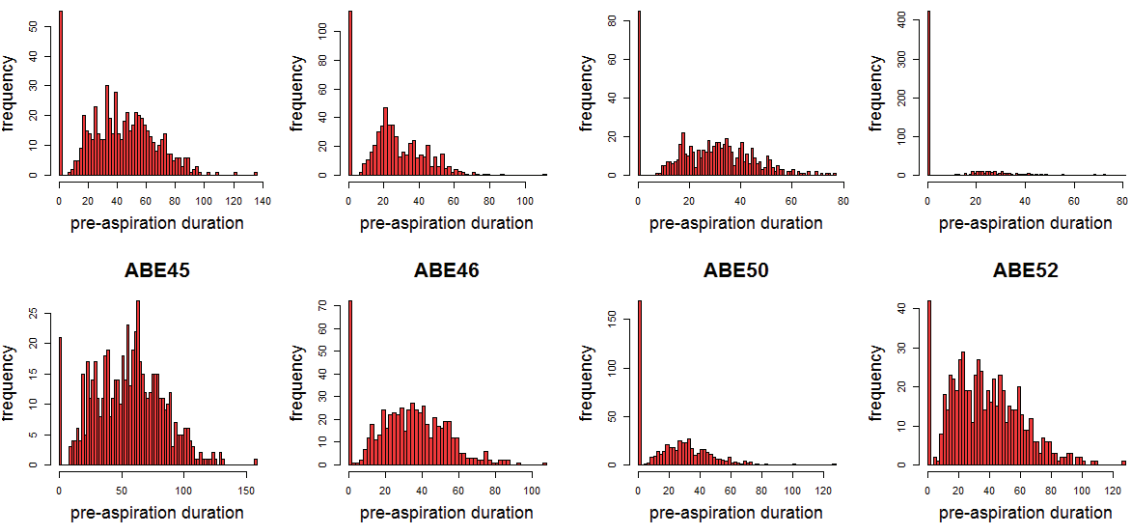

ABE52

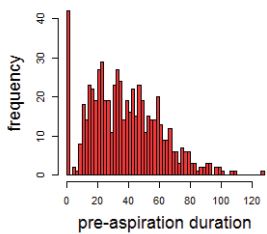

Figure 2. Distribution of the duration (ms) of voiceless pre-aspiration in 12 speakers of Aberystwyth English.

What we see is that there is one peak (or one mode) associated with zero and another peak (or another mode) which is centred around a non-zero value, e.g. around about $60 \mathrm{~ms}$ for speaker ABE45 and $30 \mathrm{~ms}$ for speaker ABE18. In addition, there is a gap between the first mode and the second mode; in other words, these two modes do not overlap. ${ }^{6}$ This detail reveals that pre-aspiration in Aberystwyth English is not subject solely to phonetic rules, for which a gradient (unimodal) outcome would be predicted. Instead,

6 The reviewer poses the interesting question of whether it is physiologically possible not to have this gap, i.e. whether it is possible for pre-aspiration to reach for instance 2 or 3 ms of duration. Physiologically, there does not seem to be any reason for pre-aspiration not to occur with the duration of 2 or $3 \mathrm{~ms}$. However, two other possible explanations may be relevant. Firstly, there may be an annotation bias: is an annotator likely to spot pre-aspiration of $2 \mathrm{~ms}$ ? Secondly, the gap may be related to perceptual biases: it may be that pre-aspiration is not perceptible unless it reaches a certain period of duration. This perceptual bias would however have to be linked with pre-aspiration being phonological in some (broad) sense, i.e. with pre-aspiration being subject to functional rather than purely phonetic - physiological and/or aerodynamic constraints. 
we see a clearly bimodal distribution, which suggests the presence of two distinct categories. The distance between zero and non-zero values of preaspiration duration is an abrupt one. In the Aberystwyth data, lumping zero values together with non-zero values may therefore potentially skew the results related to the durational properties of pre-aspiration, and this may potentially lead to erroneous understanding of how pre-aspiration innovates and which constraints it is locally and universally subject to. To demonstrate this on a specific example, if pre-aspiration occurs the least frequently with high vowels (see e.g. Hejná 2015: chapters 3 and 4, and Morris \& Hejná 2019), is it really surprising that it is also shorter in the context of high vowels, considering all the cases of pre-aspiration absence (i.e. those that reach the duration of $0 \mathrm{~ms}$ ) are included in the durational measurements as well?

It may of course be the case that the presence of a bimodal distribution (such as the one shown in Figure 2; for classical examples see also Lisker \& Abramson 1964: 400-408; Scobbie 2002) could be accounted for by confounding variables and/or a combination of a range of phonetic variables. However, the twelve speakers of Aberystwyth English used here show results based on their production of the same words, read in the same order across the speakers, and under the same conditions. Confounding factors therefore cannot account for the bimodal distribution observed. In addition, it is also not the case that the zero peak would be associated with any specific segmental or prosodic environment, or a combination of any of these. In other words, it is not the case that once we discard, for instance, foot-final cases of pre-aspiration (e.g. bat $\left[\right.$ bat $\left.^{\mathrm{s}}\right]$ ), the zero peak disappears. The author has inspected variables which include foot position, vowel height, vowel backness/rounding, vowel length, place of articulation of the plosive, and the type of the consonant preceding the vocalic sonorant and the pre-aspirated plosive, in all the possible combinations, and the conclusion is that the Aberystwyth English data presents us with no impossible environments that would account for the zero peak.

Other tests are frequently used (and ideally combined with the bimodality test) to diagnose whether a phenomenon is subject to phonological conditioning within the same environment. In case of preaspiration, Hejná (2015: chapter 4) designed a series of tests of the following type. If pre-aspiration is conditioned by phonetic vowel height as opposed to phonological vowel height, it should be the case that within each vowel phoneme, F1 is correlated positively with pre-aspiration duration, i.e. the higher the F1 (and the lower the vowel), the longer the pre-aspiration. 
However, I find that this is not borne out in the Aberystwyth English data, and conclude that phonetic factors alone cannot account for the variation in the implementation of pre-aspiration as produced in the speakers analysed in the study.

Although I have shown an example in which zero values present a separate mode of the distribution of pre-aspiration duration, it may be the case that in some languages and varieties zero values form part of a unimodal distribution. In such cases, it is of course absolutely legitimate to include these in the analyses of phonetic constraints on pre-aspiration. That this does happen is illustrated in Figure 3, which displays the distribution of the duration of local breathiness for one of the Aberystwyth speakers (and thus also demonstrates that the voiced and the voiceless components of pre-aspiration may not be subject to the same constraints). ${ }^{7}$

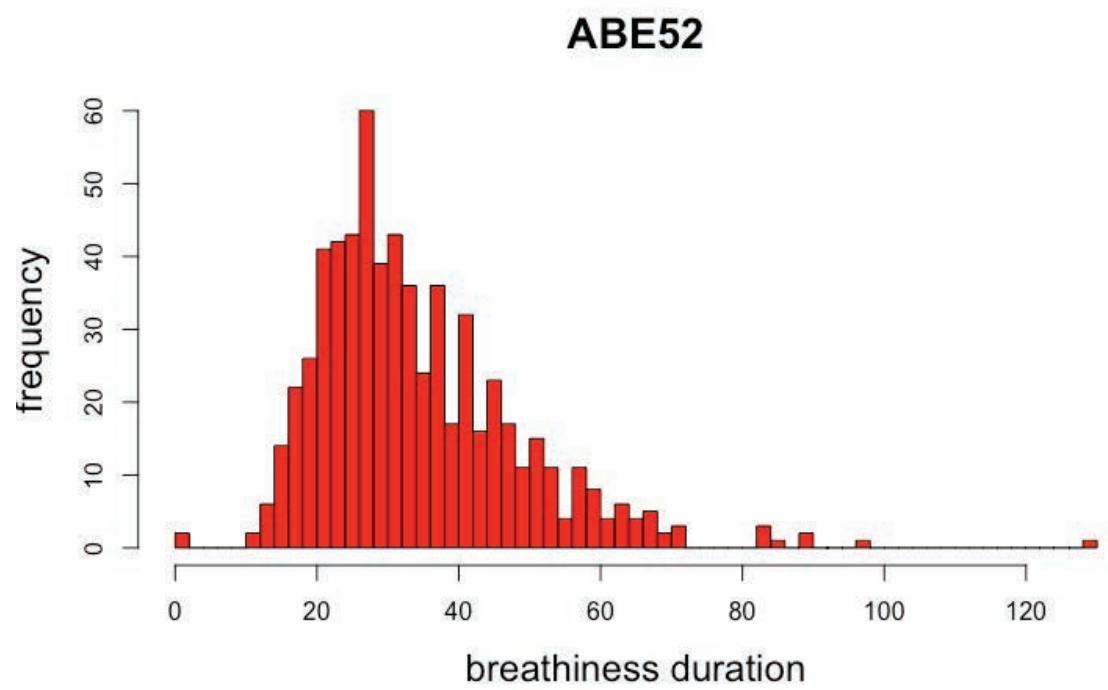

Figure 3. Distribution of the duration (ms) of local breathiness in 1 speaker of Aberystwyth English.

It may well be the case that in most of the studies of pre-aspiration in which zero values are included in the continuous measurements, the phenomenon does not display a bimodal distribution. Nonetheless, unless

7 However, in this case the few tokens associated with zeroes are historically a remnant of a bimodal distribution, as suggested by the apparent-time analysis conducted by Hejná (2015: chapter 7). 
this is inspected first, zero values should not be by default included in such measurements and their interpretation. As such, researchers working on pre-aspiration should report whether zero values are part of a unimodal distribution.

\section{Conclusion}

To summarise, assuming that cases where pre-aspiration does not apply are necessarily due to phonetic constraints is problematic. Instead, zero values of pre-aspiration duration can reflect a variable phonological rule, or a mixture of a phonological rule and phonetic constraints, or even a mixture of multiple phonological and phonetic constraints. When approaching instances of non-obligatory pre-aspiration, we should ideally inspect our data to shed light on whether a phonological conditioning of such variation can be ruled out before proceeding to purely phonetic explanations.

Now the zero has a new name [...]

(Tanning 2011)

\section{Happy birthday, Sten}

Dear Sten, I will never forget your comment on English pre-aspiration that you made during a seminar session I gave on analysing variation and change in glottalisation and pre-aspiration in English accents. This session was part of a BA Project course which we co-taught in Autumn 2017 ("BA Project: Contemporary Variation in English Dialects - As the Music Changes, You Change Too"). Sadly, we didn't have time to address your comment fully during the seminar (or after the seminar), but I hope that this paper will shed at least a wee bit of light on my hesitation as to the statement that pre-aspiration isn't phonological in English accents, as opposed to the situation found in the traditionally pre-aspirating languages such as Icelandic. I also hope this paper will make you smile and, who knows, perhaps wiggle with a bit of joy too. 


\section{References}

Anttila, Arto. 2006. Variation and phonological theory. In J. K. Chambers, Peter Trudgill \& Natalie Schilling-Estes (eds.), The handbook of language variation and change, 206-243. Blackwell Publishing: Carlton. doi:10.1002/9780470756591.ch8.

Bosch, Anna. 2006/2007. Revisiting preaspiration: evidence from the survey of Gaelic dialects of Scotland. Proceedings of the Harvard Celtic Colloquium 26/27. 269-290.

Coetzee, Andries and Joe Pater. 2011. The place of variation in phonological theory. In John A. Goldsmith, Jason Riggle \& Alan C. L. Yu (eds.), The handbook of phonological theory, 2nd edn., 401-431. Wiley Blackwell: Oxford. doi:10.1002/9781444343069.

Clayton, Ian D. 2010. On the natural history of preaspirated stops. Chapel Hill, NC: University of Carolina at Chapel Hill University dissertation.

Cohn, Abigail C. 1998. The phonetics-phonology interface revisited. Where's phonetics? Proceedings of the 1998 Texas Linguistics Society Conference. Texas Linguistic Forum 41. 25-40.

Cohn, Abigail C. 2006. Is there gradient phonology? In Gisbert Fanselow, Caroline Féry, Matthias Schlesevsky \& Ralf Vogel (eds.), Gradience in grammar: Generative perspectives, 25-44. OUP: Oxford. doi:10.1093/acprof :oso/9780199274796.001.0001.

DiCanio, Christian T. 2012. The phonetics of fortis and lenis consonants in Itunyoso Trique. International Journal of American Linguistics 78(2). 239-272. doi:10.1086/664481.

Dommelen, Wim A. van. 1998. Production and perception of preaspiration in Norwegian. Proceedings of FONETIK 1998, Stockholm. 20-23.

Dommelen, Wim A. van. 1999. Preaspiration in intervocalic $/ \mathrm{k} / \mathrm{vs}$. $/ \mathrm{g} / \mathrm{in}$ Norwegian. Proceedings of the 14th International Congress of Phonetic Sciences, San Francisco. 2037-2040.

Dommelen, Wim A. van. 2000. Preaspiration in Norwegian: Some results on speakers age, gender, and linguistic factors. Proceedings of FONETIK 2000, Skövde. 141-144.

Dommelen, Wim A. van, Snefrid Holm \& Jacques Koreman. 2011. Dialectal feature imitation in Norwegian. Proceedings of the 17th International Congress of Phonetic Sciences, Hong Kong. 599-602.

Foulkes, Paul, Gerry Docherty, and Dominic Watt. 1999. Tracking the emergence of structured variation - realisations of $(\mathrm{t})$ by Newcastle children. Leeds Working Papers in Linguistics and Phonetics 7. 1-23.

Gordeeva, Olga \& James Scobbie. 2010. Preaspiration as a correlate of wordfinal voice in Scottish English fricatives. In Susanne Fuchs, Martine Toda \& Marzena Zygis (eds.), Turbulent sounds: An interdisciplinary guide, 167-207. Mouton de Gruyter: Berlin. doi: 10.1017/S0025100314000413. 
Gordeeva, Olga \& James Scobbie. 2013. A phonetically versatile contrast: pulmonic and glottalic voicelessness in Scottish English obstruents and voice quality. Journal of the International Phonetic Association (JIPA) 43. 249-271. doi:10.1017/S0025100313000200.

Guy, Gregory R. 1991. Explanation in variable phonology: On exponential model of morphological constraints. Language Variation and Change 3(1). 1-22. doi:10.1017/S0954394500000429.

Guy, Gregory R. 1994. The phonology of variation. In Katharine Beals (ed.), CLS 30: Papers from the 30 th Regional Meeting of the Chicago Linguistic Society. Volume 2: The parasession on variation in linguistic theory, 133-149. Chicago Linguistic Society: Chicago.

Hejná, Míša. 2015. Pre-aspiration in Welsh English: A case study of Aberystwyth. Manchester, UK: University of Manchester dissertation.

Hejná, Míša. 2016. Multiplicity of the acoustic correlates of the fortis-lenis contrast: Plosives in Aberystwyth English. Proceedings of INTERSPEECH, San Francisco. 3147-3151.

Hejná, Míša and Anna Jespersen. 2019. Focus on consonants: Prosodic prominence and the fortis-lenis contrast in English. In Anne Mette Nyvad, Míša Hejná, Anders Højens, Anna Jespersen \& Mette Hjorten Sørensen (eds.), A sound approach to language matters. In honor of Ocke-Schwen Bohn, 237-270. Aarhus University Publishing Services: Aarhus. doi:10.7146/aul.322.218.

Hejná, Míša and Wendell Kimper. 2019. Pre-closure laryngeal properties as cues to the fortis-lenis plosive contrast in British varieties of English. In Ewelina Wojtkowiak (ed.), Yearbook of the Poznań Linguistic Meeting 2017 4(1). 179211. Mouton de Gruyter: Berlin. doi:10.2478/yplm-2018-0008.

Helgason, Pétur. 1998. Preaspiration in Swedish and its implications for historical sound change. Proceedings of FONETIK 1998, Stockholm. 16-19.

Helgason, Pétur. 1999a. Preaspiration and sonorant devoicing in the Gräsö dialect: preliminary findings. Proceedings of FONETIK 1999, Gothemburg. 77-80.

Helgason, Pétur. 1999b. Phonetic preconditions for the development of normative preaspiration. Proceedings of the 14th International Congress of Phonetic Sciences, San Francisco. 1851-1854.

Helgason, Pétur. 2002. Preaspiration in the Nordic languages. Synchronic and diachronic aspects. Stockholm, Sweden: Stockholm University dissertation.

Helgason, Pétur. 2003. Faroese preaspiration. Proceedings of the 15th International Congress of Phonetic Sciences, Barcelona. 2517-2520.

Helgason, Pétur and Catherine Ringen. 2008. Voicing and aspiration in Swedish stops. Journal of Phonetics 36. 607-628. doi:10.1016/j.wocn.2008.02.003.

Iosad, Pavel. 2016. Rule scattering and vowel length in Northern Romance. Papers in Historical Phonology 1. 218-237. doi:10.2218/pihph.1.2016.1700.

Jones, Mark and Carmen Llamas. 2003. Fricated pre-aspirated / $t$ / in Middlesbrough English: An acoustic study. Proceedings of the 15th International Congress of Phonetic Sciences, Barcelona. 655-658. 
Keating, Patricia A. 1990. Phonetic representations in a generative grammar. Journal of Phonetics 18. 321-334.

Keating, Patricia A. 1996. The phonology-phonetics interface. Studia Grammatica 41. In Ursula Kleinhenz (ed.), Interfaces in phonology, 262-278. Akademie Verlag: Berlin.

Kingston, John. 1990. Articulatory Binding. In John Kingston \& Mary E. Beckman (eds.), Papers in Laboratory Phonology I. Between the Grammar and the Physics of Speech, 406-434. Cambridge University Press: Cambridge. doi:10.1017/CBO9780511627736.023.

Ladefoged, Peter and Ian Maddieson. 1996. The sounds of the world's languages. Blackwell: Oxford.

Lisker, Leigh and Arthur S. Abramson. 1964. A cross-language study of voicing in initial stops: acoustical measurements. Word 20. 384-422. doi:10.1080/0043 7956.1964.11659830.

McRobbie-Utasi, Zita. 2003. Normative preaspiration in Skolt Sami in relation to the distribution of duration in the disyllabic stress-group. In Zita McRobbieUtasi (ed.), Honti-Festschrift, 291-300. C. So. Hungarian Academy of Sciences, Institute of Linguistics: Budapest.

Morris, Jonathan. 2010. Phonetic variation in Northern Wales: Preaspiration. Proceedings of the Second Summer School of Sociolinguistics. Eds. M. Meyerhoff, C. Adachi, A. Daleszynska A. Strycharz. University of Edinburgh: Edinburgh, http://www.lel.ed.ac.uk/sssocio/proceedings/Jon.pdf (3 September 2012).

Morris, Jonathan \& Míša Hejná. 2019. Pre-aspiration in Bethesda Welsh: A sociophonetic analysis. Journal of the International Phonetic Association (JIPA). doi:10.1017/S0025100318000221.

Nance, Claire \& Jane Stuart-Smith. 2013. Pre-aspiration and post-aspiration in Scottish Gaelic stop consonants. Journal of the International Phonetic Association (JIPA) 43(2). 129-152. doi:10.1017/S0025100313000042.

Ní Chasaide, Ailbhe. 1985. Preaspiration in phonological stop contrasts. Bangor, UK: University College of North Wales dissertation.

Ohala, John J. 1990. There is no interface between phonology and phonetics: A personal view. Journal of Phonetics 18. 153-171.

Pind, Jörgen. 1996a. Rate dependent perception of aspiration and pre-aspiration in Icelandic. The Quarterly Journal of Experimental Psychology. Section A: Human Experimental Psychology 49(3). 745-764. doi:10.1080/713755645.

Pind, Jörgen. 1996b. Rate-dependent perception of quantity in released and unreleased syllables in Icelandic. Speech Communication 19. 295-306. doi:10.1016/S0167-6393(96)00051-9.

Pind, Jörgen. 1998. Auditory and linguistic factors in the perception of voice offset time as a cue for preaspiration. Journal of the Acoustical Society of America (JASA) 103(4). 2117-2127. doi:10.1121/1.421357. 
Ringen, Catherine and Dommelen, Wim A van. 2013. Quantity and laryngeal contrasts in Norwegian. Journal of Phonetics 41. 479-490. doi:10.1016/j. wocn.2013.09.001.

Roos, Marti. 1998. Preaspiration in Western Yugur monosyllables. The Mainz Meeting. Proceedings of the Seventh International Conference on Turkish Linguistics August 3-6, 1994. / Turgologica 32. 28-41.

Scobbie, James. 2002. Flexibility in the face of incompatible English VOT systems. Laboratory Phonology 8. 367-392.

Sebregts, Koen. 2014. The sociophonetics and phonology of Dutch $r$. LOT: The Netherlands.

Silverman, Daniel. 2003. On the rarity of pre-aspirated stops. Journal of Linguistics 39. 575-598. doi:10.1017/S002222670300210X.

Stevens, Mary. 2010. How widespread is preaspiration in Italy? A preliminary acoustic phonetic overview. Lund University Centre for Languages and Literature Phonetics Working Papers 54. I Proceedings of FONETIK 2010, Lund. 97-102.

Stevens, Mary. 2011. Consonant length in Italian: gemination, degemination and preaspiration. Selected Proceedings of the 5th Conference on Laboratory Approaches to Romance Phonology. 21-32.

Stevens, Mary and John Hajek. 2004a. Comparing voiced and voiceless geminates in Sienese Italian: what role does preaspiration play? Proceedings of the 10th Australian International Conference on Speech Science \& Technology. 340305.

Stevens, Mary and John Hajek. 2004b. Preaspiration in Sienese Italian and its interaction with stress in /VC:/ sequences. Proceedings of Speech Prosody, Nara. 57-60.

Strycharczuk, Patricia. 2012. Phonetics-phonology interactions in pre-sonorant voicing. Manchester, UK: University of Manchester dissertation.

$\mathrm{Su}$, Venetia W. Y. 2007. The gender variable in Australian English stop consonant production. Melbourne, Australia: The University of Melbourne dissertation.

Svantesson, Jan-Olof, Anna Tsedina, Anastasia Karlsson and Vivan Franzén. 2005. The phonology of Mongolian. Oxford University Press: Oxford. doi:10.1017/ S095267570999025X.

Svantesson, Jan-Olof and Anastasia Karlsson. 2012. Preaspiration in Modern and Old Mongolian. Suomalais-Ugrilaisen Seuran Toimituksia [Mémoires de la Société Finno-Ougrienne] 264. 453-464.

Tronnier, Mechtild. 2002 Preaspiration in Southern Swedish dialects. Proceedings of FONETIK 2002, Stockholm. I Quarterly Progress and Status Report, Department of Speech, Music and Hearing and Centre for Speech Technology. KTH: Stockholm 44. 33-36.

Tanning, Dorothea. 2011. Zero. Coming to that. Minneapolis: Graywolf Press. 
Turton, Danielle. 2014. Variation in English /l/: Synchronic reflections of the life cycle of phonological processes. Manchester, UK: University of Manchester dissertation.

Turton, Danielle. 2015. Determining categoricity in English /1/-darkening: A principal component analysis of ultrasound spline data. Proceedings of the 18th International Congress of Phonetic Sciences, Glasgow.

Turton, Danielle. 2017. Categorical or gradient? An ultrasound investigation of /1/darkening and vocalization in varieties of English. Laboratory Phonology 8(1). 1-31. doi:10.5334/labphon.35.

Wretling, Pär, Eva Strangert \& Felix Shaeffler. 2002. Quantity and preaspiration in Northern Swedish dialects. Proceedings of Speech Prosody 2002, Aix-enProvence, France, 11-13 April 2002. 703-706. 